Palabra Clave (La Plata)

ISSN: 1853-9912

palabraclave@fahce.unlp.edu.ar

Universidad Nacional de La Plata

Argentina

\title{
Uso seguro da informação: uma análise na base de dados SCOPUS
}

de C. S. Casarin, Helen; de Paulo, Rodrigo Barbosa

Uso seguro da informação: uma análise na base de dados SCOPUS

Palabra Clave (La Plata), vol. 9, núm. 2, 2020

Universidad Nacional de La Plata, Argentina

Disponible en: http://www.redalyc.org/articulo.oa?id=350562513002

DOI: https://doi.org/10.24215/18539912e089 


\section{Uso seguro da informação: uma análise na base de dados SCOPUS}

Safe use of information: an analysis of the SCOPUS database

Helen de C. S. Casarin

Universidade Estadual Paulista - UNESP, Brasil

helen.castro@unesp.br

DOI: https://doi.org/10.24215/18539912e089

Redalyc: http://www.redalyc.org/articulo.oa?

Rodrigo Barbosa de Paulo

Universidade Estadual Paulista - UNESP. Doutorando

do Programa de Pós-Graduação em Ciência da Informação,

Brasil

rodrigodepaulo22@hotmail.com

\section{Resumo:}

O acesso à informação através da internet ganha a cada dia mais espaço em nossa sociedade, inclusive entre crianças e adolescentes. $\mathrm{O}$ estudo teve como objetivo identificar tendências de pesquisas sobre o uso seguro da informação on line por crianças e adolescentes relacionadas à competência informacional. Foi realizado um levantamento na base de dados SCOPUS e após refinamento dos resultados obteve-se 71 referências. Como os resultados observou-se que os Estados Unidos e o Reino Unido são os países que mais publicam sobre a temática e que $52.9 \%$ das produções se tratam de artigos científicos. Verificou-se que os documentos analisados ressaltam a importância de que orientações sobre o tema ocorram na escola, com destaque para o papel da biblioteca escolar, visto que na escola pública este é o local em que os estudantes mais acessam a internet. Verificou-se também que o tema uso seguro da informação abrange muitos outros subtemas: exposição de dados, abuso sexual, cyberbullying. Concluiu-se que a pesquisa sobre uso seguro da informação em ambientes online é complexa e que a área carece de pesquisas sobre a temática, em particular no Brasil, visando obter mais subsídios que permitam conhecer melhor esta questão e tendo a escola como espaço de aplicação, discussão e orientação que possibilite o desenvolvimento de habilidades para uma navegação mais segura por adolescentes.

PalaVRas-CHAVE: Segurança da informação, Usuários de informação, Competência em informação, Redes sociais.

\section{Abstract:}

Access the information using the internet is gaining more and more space in our society, including among children and adolescents. The study aimed to identify research trends related to the safe use of online information and the development of information literacy. A survey was performed in the SCOPUS database and after refining the results, 71 references were obtained. As a result it is observed that the United States and the United Kingdom are the largest producers of content on the subject, 52.9\% of the productions are through scientific articles. It was found that the documents underscore the importance of guidance on the subject in the school, especially the school library in this process, being in public school, the place that students most access the internet. It has also been found that the safe use of information theme covers many other subthemes: data exposure, sexual abuse, cyberbullying. It was concluded that the research on secure use of information in online environments is complex and that the area lacks research on the subject aiming to obtain more subsidies to better understand this issue and having the school as a space for application, discussion and guidance that enable the development of skills for safer browsing by teenagers.

KEYWORDS: Information security, Information users, Information literacy, News media.

\section{INTRODUÇÃo}

Em nossa sociedade o acesso à informação através da Internet ganhou grande espaço em diversos ambientes. Porém, existe a necessidade de se aprofundar em como as crianças e adolescentes têm utilizado a internet para o acesso, uso e produção da informação e como a escola com todos os seus recursos humanos e tecnológicos tem contribuído para o consumo, uso e produção da informação de forma consciente e segura. 
Segundo Dias e Cavalcante (2016), a internet possui um papel fundamental na mudança de hábitos e de relacionamentos, criando um ambiente de formação de identidades. Tais aspectos nos levam a questionamentos sobre como temos educado crianças e adolescentes para a utilização de uma ferramenta tão potente que interfere até mesmo na formação de identidades?

Desde o seu início em 1962, na Guerra Fria para fins militares, passando por meados de 1970 e 1980 com abertura para uso no meio acadêmico até os dias atuais, a internet atravessou por muitas transformaçóes, tornando-se cada vez mais interativa. A internet 2.0, por exemplo, permite ao usuário leigo interagir e criar seu próprio conteúdo; e a Internet das coisas, que, segundo Santaella, Gaia, Policarpo e Gazoni (2013), permite a conexão contínua entre aparelhos físicos, sem limites de espaço e tempo. Para Magrani (2018), trata-se do desenvolvimento de utensílios ligados à internet, que podem captar dados do seu ambiente.

No Brasil, a internet surgiu no ano de 1988, com maior disseminação em 1990. A partir de 2006 as redes sociais ganharam espaço na interação social, sendo pioneiro o Orkut. Hoje a preferência é por outras redes, como Instagram, WhatsApp, Twitter, Facebook, entre outros. Em de 2010, serviços online com sites de compras coletivas aumentam as vendas, além de fazer com que os consumidores não percam tempo em pontos comerciais (Dias e Cavalcante, 2016).

Este avanço, no entanto, não ocorreu de forma generalizada, pois mesmo nos dias de hoje nem todas as pessoas têm acesso a essas ferramentas. A inclusão digital interfere diretamente na inclusão social, pois quanto mais informação a pessoa tiver, mais embasada será sua tomada de decisão. O que foi apresentado até aqui possibilita a reflexão sobre que tipo de informação o sujeito/estudante está sendo exposto, mais que isto, como tem se dado os direcionamentos a esta exposição de forma segura no contexto escolar.

Observa-se que os dispositivos móveis e touchscreen conectados à internet têm possibilitado o acesso das crianças desde os primeiros meses de vida. A mídia digital e os aplicativos voltados para crianças pequenas também usam uma combinação de exibição de ícones, áudio e vídeo para fornecer instruções operacionais que permitem que as crianças acessem e interajam com a Internet independentemente da supervisão de adultos (Edwards, Nolan, Henderson, Mantila, Plowman e Skouterls et al, 2018). Crescer em um ambiente em que as pessoas estão constantemente on-line pressupõe atividade digital, que demanda uma educação sobre segurança cibernética desde os anos iniciais (Edwards, Nolan, Henderson, Mantila, Plowman e Skouterls, 2018).

É necessário compreender-se o conceito de internet para crianças em seu dia a dia, o entendimento que elas possuem sobre esta ferramenta de forma contextualizada, para somente depois, poder desenvolver junto a elas a compreensão dos conceitos científicos.

Uma analogia utilizada por Edwards, Nolan, Henderson, Mantila, Plowman e Skouterls (2018) é a educação sobre segurança no trânsito e a importância de se olhar para todos os lados antes de atravessar a rua. As crianças não precisam necessariamente saber como um carro funciona, da mesma forma com a internet. No entanto, há um valor potencial em construir conceitos sobre Internet que vão além de entretenimento, para que as crianças entendam que o que elas estão usando engloba muitas tecnologias interconectadas que permitem interações sociais entre diversas pessoas.

Neste contexto, discute-se o desenvolvimento de habilidades informacionais e seus direcionamentos no acesso e produção da informação, sem deixar de lado aspectos como a segurança em relação a este usuário da informação.

A alfabetização midiática e informacional (AMI), proporciona aos cidadãos as competências necessárias para usufruir de seu direito de opinar livremente e de procurar, receber e transmitir informações e ideias por qualquer meio (UNESCO, 2013). Diante das diversas definições, Uribe Tirado (2009) elaborou uma macrodefinição sobre competência informacional, como sendo um processo de ensino-aprendizagem em que o indivíduo alcance: (conhecimentos, habilidades e atitudes) comunicacionais, digitais e informacionais, de forma que lhes permitam utilizar diferentes formatos, meios e recursos físicos, eletrônicos ou digitais, e de modo adequado e eficientemente aplicar essa informação com uma posição crítica. Casarin (2017) diz que 
o desenvolvimento destas habilidades informacionais distingue os usuários entre os que são autônomos e os que dependem de outras pessoas para terem acesso à informação que precisam.

Com esta compreensão, este artigo tem como objetivo verificar, a partir da base de dados SCOPUS, as tendências da produção científica sobre a temática "uso seguro da informação" por crianças e adolescentes em redes sociais. Mais especificamente, procurou-se identificar os pesquisadores e periódicos que têm se dedicado à temática de segurança da informação; verificar as tendências de publicações sobre o tema; identificar as principais abordagens sobre o tema nas publicações analisadas.

\section{SEguranÇA DA INFORMAÇÃo E REDES SOCIAIS}

Haynes e Robinson (2014) relacionam a importância de se pesquisar a segurança na produção da informação nas mídias sociais e os serviços informacionais oferecidos pelas bibliotecas e bibliotecários, em suas responsabilidades quanto: educador, mediador da informação e os usuários de mídias sociais.

A compreensão destes riscos possibilita a criação de legislação para regulamentação de acesso a dados pessoais nas mídias sociais, pois a disponibilização de dados pessoais a um público amplo expõe os usuários a riscos. Haynes e Robinson (2014) definem risco como um evento de probabilidade desconhecida de ocorrência envolvendo dados pessoais num serviço de rede social, que tenha um impacto negativo. Por exemplo, os dados de um indivíduo podem ser copiados para efeitos de fraude, resultando em prejuízos financeiros.

Ao pesquisar sobre privacidade na internet pode-se pensar em: software mal-intencionados que baixam arquivos, espionam e danificam os computadores; tecnologia de geolocalização generalizada; processamento de dados e reconhecimento facial, ameaçando assim a privacidade na internet.

Estas vulnerabilidades podem ser prejudiciais aos usuários de redes sociais, por exemplo, quando o invasor divulga informações confidenciais em fórum público; altera as configurações de privacidades do usuário da rede social e coleta de dados pessoais para anunciantes, entre outros (Comitê Gestor Da Internet No Brasil, 2014).

Outros problemas podem ser causados pelos próprios usuários, tais como: postar informações inadequadas sobre si mesmos, ocasionando problemas no trabalho; publicar informações sobre outras pessoas sem a devida permissão; informar sua localização, expondo-se a roubo, entre outros (Comitê Gestor da Internet no Brasil, 2014).

Ao se pensar sobre segurança dos usuários no uso da rede web e no papel da educação em relação a esta questão, Edwards, Nolan, Henderson, Mantila, Plowman e Skouterls (2018) trazem reflexões de grande relevância apoiadas nas teorias socioculturais de Vygotsky. A construção do conhecimento para crianças ocorre através de experiências dentro de um determinado contexto. O contexto é importante porque dá origem à prática de atividades e ao uso de ferramentas culturais.

No processo de desenvolvimento da aprendizagem, muitas vezes, observa-se a utilização de conceitos que os adultos possuem sobre determinado assunto como ponto de partida, neste caso, a internet. Logo, partese deste conceito elaborado pelos adultos e emprega-se no processo de ensino-aprendizagem como se fosse o mesmo conceito que as crianças usuárias de internet teriam. Tal postura diverge da teoria de Vygotsky citada acima, segundo a qual seria interessante desenvolver a aprendizagem a partir do conceito que o sujeito envolvido neste processo tem sobre o assunto em diferentes contextos, pois, diferentes grupos de crianças podem pensar e compreender a internet de forma diferente dos adultos que compóem aquela comunidade (Edwards, Nolan, Henderson, Mantila, Plowman e Skouterls, 2018, tradução nossa).

Ao investigar como as crianças compreendem a internet, pode-se melhorar a elaboração de ações e atividades que promovam o desenvolvimento de habilidades para uma utilização mais adequada desta ferramenta e suas potencialidades, que inclui a própria segurança ao navegar neste ambiente. 


\section{CoMPETÊNCIA INFORMACIONAL E MIDIÁtica E SEGURANÇA DA INFORMAÇÃo}

$\mathrm{Na}$ sociedade da informação, contraditoriamente, há uma disparidade de acesso e uso da informação. Enquanto algumas pessoas estão sobrecarregadas, outras sofrem por falta de acesso à informação decorrente de diversos fatores dentre eles: social e econômico.

Para diminuir esta disparidade, a UNESCO (2016) propôs o conceito de AMI como sendo uma base para aumentar o acesso à informação e ao conhecimento, intensificar a liberdade de expressão e melhorar a qualidade da educação. A AMI descreve as habilidades e as atitudes necessárias para compreender e utilizar as diversas funções das mídias de forma inteligente e de outros provedores de informação, incluindo aqueles na internet, bem como para encontrar, avaliar e produzir informações e conteúdos midiáticos; em outras palavras, apresenta as competências fundamentais para que as pessoas participem de maneira eficaz de todos os aspectos do desenvolvimento das habilidades necessárias para a utilização destes veículos informacionais.

No contexto escolar, deve- se pensar como melhor introduzir e abordar a temática de forma significativa. Paulo (2016) desenvolveu uma pesquisa para compreender como os bibliotecários podem colaborar para a formação de habilidades dos professores para o desenvolvimento da competência informacional dos estudantes. Uma das constatações da pesquisa foi que apesar da existência de laboratórios de informática nas escolas pesquisadas é preciso trabalhar melhor o desenvolvimento da competência informacional dos professores, ou seja, a disponibilidade de equipamentos não garante o bom uso dos mesmos e muito menos a utilização adequada desta ferramenta no ensino.

Apesar da constante mudança da sociedade, a expressão de ideias, o ler, ouvir, escrever e produzir informações e da possibilidade de comunicação uns com os outros têm aumentado a cada vez mais. No século XXI estas competências e habilidades são desenvolvidas grandemente através das mídias e tecnologias (UNESCO, 2016).

Para que estas competências e habilidades sejam desenvolvidas de forma direcionada a colaborar com a pesquisa e a aprendizagem escolar, não somente ligada ao entretenimento, precisa-se de profissionais que trabalhem na área da educação, entre eles bibliotecários, coordenadores pedagógicos e professores, preparados para estes novos desafios. É neste contexto que a alfabetização midiática e informacional (AMI) deve ser vista como necessária, ela expande o movimento pela educação que inclui os professores como os principais agentes de mudança (UNESCO, 2013).

Recentemente no Brasil, foi lançada a Base Nacional Comum Curricular (BNCC), na qual se propõe que toda a educação básica brasileira esteja voltada para o desenvolvimento de competências e habilidades, o que reforça o entendimento do estado brasileiro das necessidades de aprendizagem que correspondam às demandas do estudante desta época, preparando-o para o futuro, considerando que as propostas da base sejam colocadas em prática.

$\mathrm{Na}$ BNCC, define-se competência como a mobilização de conhecimentos (conceitos e procedimentos), habilidades (práticas, cognitivas e socioemocionais), atitudes e valores para resolver demandas complexas da vida cotidiana (Ministério da Educação, 2018).

Entre as dez competências gerais relacionadas no documento (Ministério da Educação, 2018), destaca-se, na discussão deste artigo, as competências cinco e sete:

5. Compreender, utilizar e criar tecnologias digitais de informação e comunicação de forma crítica, significativa, reflexiva e ética nas diversas práticas sociais (incluindo as escolares) para se comunicar, acessar e disseminar informações, produzir conhecimentos, resolver problemas e exercer protagonismo e autoria na vida pessoal e coletiva;

7. Argumentar com base em fatos, dados e informações confiáveis, para formular, negociar e defender ideias, pontos de vista e decisões comuns que respeitem e promovam os direitos humanos, a consciência socioambiental e o consumo responsável em âmbito local, regional e global, com posicionamento ético em relação ao cuidado de si mesmo, dos outros e do planeta. 
As duas competências acima se destacam, pois, ambas reforçam o papel da escola no desenvolvimento da competência informacional. O desenvolvimento destas duas competências é necessário diante do grande volume de informação acessado facilmente através, por exemplo, de um dispositivo móvel conectado à internet.

Na prática diária de uma biblioteca, observa-se que os estudantes possuem boa competência e habilidades desenvolvidas em utilizar as tecnologias digitais quando a busca se relaciona a entretenimento, jogos, ou redes sociais. Quando se trata de desenvolver uma pesquisa ou buscar informações que não contemplam as finalidades acima, percebe-se uma grande defasagem, mesmo em atividades rotineiras como busca de informação em um site ou preenchimento de uma ficha de inscrição. A BNCC (Ministério Da Educação, 2018) é uma proposta que aponta para a mudança desta realidade.

A BNCC (Ministério Da Educação, 2018) foi desenvolvida alinhada com a Agenda 2030 da ONU (2015) e seus 17 objetivos e 169 metas. Nesta discussão, destaca-se o Objetivo 4 do Desenvolvimento Sustentável, o qual busca assegurar a educação inclusiva e equitativa e de qualidade e promover oportunidades de aprendizagem ao longo da vida para todos.

Este objetivo de desenvolvimento sustentável que aborda diretamente questões relacionadas à educação, possui grande relevância, pois afirma na meta 4.4 a necessidade de se aumentar habilidades relevantes de jovens e adultos. Nestas habilidades se pode incluir as habilidades informacionais e consequentemente de saber utilizar e produzir a informação de forma segura.

Segundo o Núcleo de Informação e Coordenação do Ponto BR (https://www.nic.br/sobre/) (NIC. $\mathrm{Br}, 2018)$, deve-se buscar estratégias educacionais para a promoção do acesso qualitativo e equitativo às tecnologias nas escolas de forma que os estudantes participem das dinâmicas sociais, culturais, políticas e econômicas por meio das tecnologias, assim como ofertar subsídios para que os professores estejam preparados para apoiá-los na compreensão e na apropriação de tais dinâmicas.

Para compreender o tamanho do desafio a ser enfrentado, são apresentados alguns resultados da pesquisa NIC. $\mathrm{Br}$ (2018) sobre o uso das tecnologias de informação e comunicação nas escolas brasileiras no ano de 2017. De acordo com o que foi verificado na referida pesquisa: $22 \%$ dos estudantes de escolas públicas acessam a internet exclusivamente pelo celular, diferentemente dos estudantes de escola particular, somente 2\%; 44\% dos professores de escolas públicas e 61\% dos professores de escolas particulares disponibilizaram conteúdo na Internet para os alunos; $40 \%$ do total de professores haviam ajudado algum aluno a enfrentar situações ocorridas na Internet, tais como bullying, discriminação, assédio e disseminação de imagens sem consentimento. Percentual que é bastante semelhante entre professores que lecionam em escolas públicas (39\%) e que lecionam em escolas particulares (44\%); 60\% dos estudantes de escolas públicas e privadas receberam orientação sobre a utilização de fontes de informação, porém, apenas $33 \%$ recebeu orientação caso sofressem algum incômodo.

A pesquisa realizada pelo NIC.br (2018) demonstra que 66\% de estudantes de escolas públicas e $67 \%$ das privadas, compartilharam na internet um texto, imagem ou vídeo, porém somente $33 \%$ destes estudantes receberam orientações sobre segurança da informação. Este dado mostra como os estudantes estão expostos sem receber nenhuma orientação a respeito do uso da internet com segurança.

A pesquisa também aponta que a maior parte do acesso à internet é feito por uso exclusivo do celular, o que provavelmente envolve questões econômicas entre os estudantes de escola pública. Outra informação importante é sobre o número de estudantes que receberam orientação caso sofressem algum incômodo. Mesmo com o grande número de estudantes acessando a internet, menos da metade recebeu informação sobre como utilizar esta ferramenta com segurança.

Para minimizar este problema, além da formação dos professores, é necessário o envolvimento de toda a instituição na incorporação da educação para o uso das tecnologias no currículo escolar e a parceria entre professores, pais e responsáveis, tanto nas ações de prevenção, quanto no gerenciamento da ocorrência de possíveis incidentes estão entre as melhores práticas, segundo a NIC.br (2018). 
Outra pesquisa que colabora para a compreensão e direcionamentos para uma navegação segura foi realizada nos anos de 2017/2018 pela EU Kids online, que é uma rede de pesquisa multinacional que procura melhorar o conhecimento das oportunidades, riscos e segurança online das crianças europeias. A pesquisa foi financiada pelo programa Better Internet for Kids da CE e utiliza vários métodos para mapear a experiência das crianças e dos pais na Internet, em diálogo com as partes interessadas das políticas nacionais e europeias.

Os estudos analisaram os dados de amostras nacionalmente representativas de crianças de 9 a 17 anos, em cinco países europeus: Estônia, Itália, Noruega, Eslováquia e República Tcheca. A pesquisa mostrou que em um grupo de 25 crianças e adolescentes dos cincos países da amostra, os problemas com a segurança da informação foram: pegar algum vírus espião; uso de senha para acessar informação pessoal de outra pessoa; gasto de dinheiro em aplicativos de jogos on line, perda de dinheiro por trapaça na internet e localização geográfica por informação fornecida pelo telefone ou dispositivos (EU Kids on line, 2019).

Através dos resultados das pesquisas feitas com crianças europeias, pode-se fazer uma prospecção dos maiores riscos que crianças brasileiras estão expostas ao utilizar a internet sem a devida segurança e traz a reflexão sobre como tem ocorrido a formação de professores nas escolas brasileiras. Um dos maiores responsáveis pela formação dos professores nas escolas é o coordenador pedagógico.

Em uma pesquisa avaliativa do ano de 2017 o NIC.br (2018) apresenta uma análise comparativa entre escolas públicas e privadas, de atividades de promoção de uso seguro da internet pelos coordenadores pedagógicos. Os dados mostram que, entre as escolas pesquisadas, $80 \%$ dos professores das escolas privadas tinham recebido orientação para direcionar o uso seguro da internetpelos estudantes e somente $57 \%$ dos professores de escolas públicas a receberam (NIC.br, 2018). Ou seja, se os próprios professores como formadores não têm recebido estas orientações, o que esperar do comportamento dos estudantes nestes espaços?

O Marco Civil da Internet (Brasil, 2014) diz no artigo 26 que as iniciativas de formação para o uso seguro, consciente e responsável da Internet fazem parte das atribuições do Estado em todos os níveis de ensino, devendo ser ofertadas de forma integrada às atividades curriculares (Brasil, 2014). No entanto, segundo a mesma pesquisa citada acima, em 2017, apenas 14\% dos diretores de escolas públicas e 19\% dos diretores de escolas particulares afirmaram conhecer o documento (NIC.br, 2018).

Conforme dados do Nic.br (2018), nos resultados dos últimos três anos a biblioteca é o local em que os professores das escolas públicas mais acessam a internet, seguida da sala de aula e do laboratório de informática. Esta diferença, no entanto, vem decrescendo e no resultado dos últimos dois anos a biblioteca e a sala de aula são utilizados de forma praticamente igual com discreto destaque para as bibliotecas. Já em relação às escolas privadas a sala de aula se mantém nos três anos de pesquisa como principal local de acesso à internet pelos professores.

\section{Metodologia}

O estudo aqui relatado possui caráter descritivo com abordagens qualitativa e quantitativa, com o objetivo verificar a produção científica sobre o tema: uso seguro da informação nas redes sociais por crianças e adolescentes na base de dados SCOPUS.

O corpus da pesquisa é formado por artigos de periódicos indexados na SCOPUS, que é a maior base de dados de resumos e citações revisadas por pares, incluindo revistas científicas, livros e anais de eventos, cobrindo tópicos de pesquisa em todas as disciplinas técnicas e científicas, com curadoria de mais de 5.000 publicadores e mais de 195 milhões de referências citadas (SCOPUS, 2019).

Ao considerar que SCOPUS é uma base de dados internacional, foi definida a seguinte estratégia de busca: ( ( internet OR "socialmedia") AND (child OR children OR adolescente OR teen) AND ("online SECURITY" OR "cyber secutity" OR "online safety" OR "Cyber safety")). 
Com esta estratégia foram recuperadas 105 referências, das quais foram analisados: título, resumo e palavras-chave (article title, abstract, keywords) considerando a temática e área da pesquisa.

Um segundo refinamento por exclusão de autores foi necessário, pois somente a leitura dos metadados dos textos, conforme apontado acima, não permitiu ter clareza do objetivo e da área de assunto a que pertenciam os textos. Em alguns casos houve a necessidade de analisar tópicos do corpo do artigo ou a sua conclusão.

Assim, verificou-se a área de pesquisa dos autores recuperados. Como os autores, de forma geral, seguem uma mesma linha de pesquisa, caso um determinado autor fosse excluído após a análise, os demais artigos deste mesmo autor também foram excluídos. Desta forma chegou-se ao número de 71 referências consideradas positivas (Apêndice), as quais serão analisadas nas próximas seções deste artigo.

Como a base de dados SCOPUS abrange as diversas áreas do conhecimento, observou-se que o tema "uso seguro da informação na internet" vem sendo abordado por várias áreas do conhecimento além da ciência da informação.

É interessante observar a diversidade de assuntos que estão relacionados em uma mesma temática. Recuperou-se, por exemplo, artigos da área da saúde, trazendo aspectos emocionais e sociais que fragilizam e tornam os adolescentes possíveis vítimas de cyberbullying e possíveis vítimas de comportamento não seguro na internet. Estes artigos não foram incluídos nesta pesquisa, por terem como foco características emocionais e sociais dos indivíduos, por exemplo: baixa escolaridade da mãe, divórcio, maus tratos, desemprego do pai etc. Embora estas características sejam de grande importância para compreender o grupo de crianças ou adolescentes observados, o foco desta pesquisa é a competência informacional, ou seja, quais habilidades devem ser desenvolvidas para que este estudante consiga navegar na internet de forma segura.

A coleta de dados foi realizada em 19 de fevereiro de 2019, abrangendo o período temporal até 2018.

Com base na análise de conteúdo deste conjunto de 71 resultados, foram identificadas algumas características que serão, detalhadamente, apresentadas e discutidas na próxima seção deste trabalho.

\section{Resultados E Discussão}

Um primeiro aspecto que se pode observar no gráfico 1 é o país de origem das produções sobre tema recuperadas na base de dados SCOPUS.

FIGURA 1

Documentos por localização geográfica

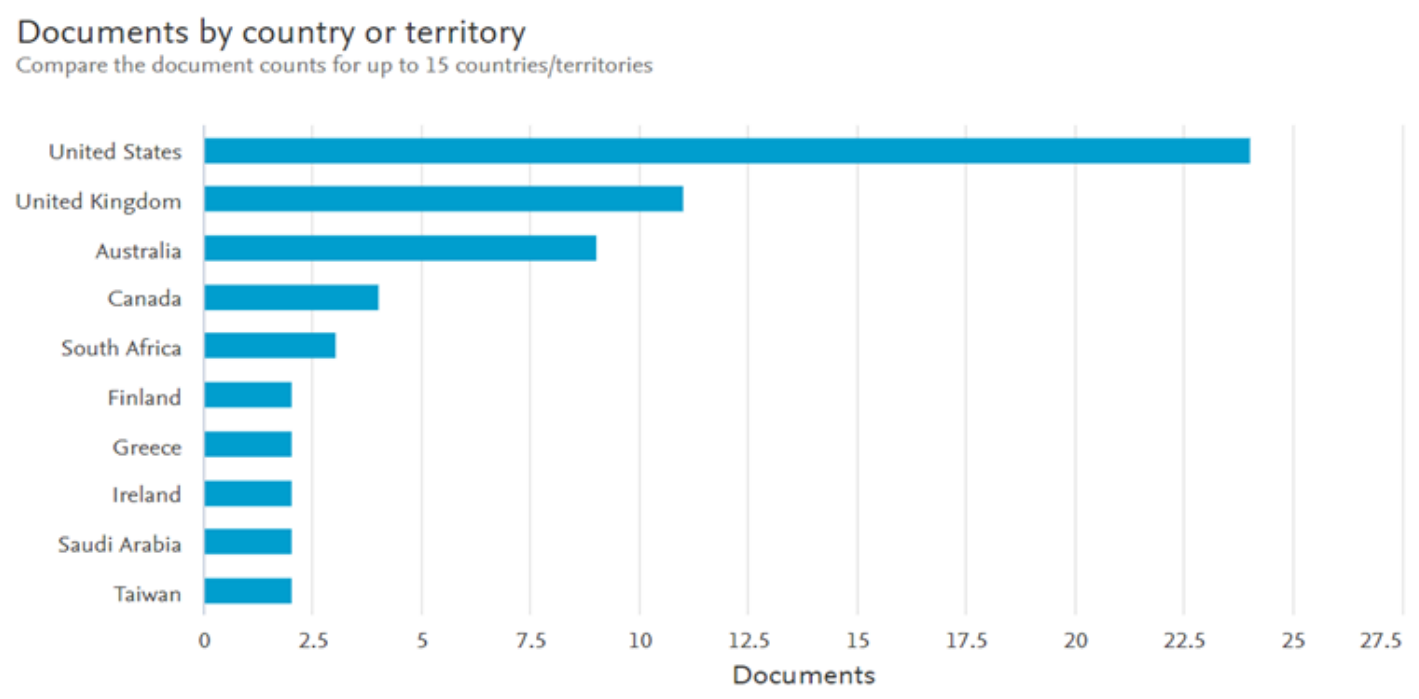




\section{Fonte: SCOPUS.}

Como se pode observar no gráfico 1, o país que mais possui artigos relacionados à temática é os Estados Unidos, seguido do Reino Unido, Austrália, Canadá, África do Sul. Já a Finlândia, Grécia, Irlanda, Arábia Saudita e Taiwan têm respectivamente dois artigos publicados.

Com a estratégia de busca utilizada, não foi localizada nenhuma publicação brasileira na base de dados SCOPUS, mas apenas uma publicação em português pertencente a Portugal. O que leva ao questionamento do por que não há publicações brasileiras sobre o tema na base?

Deve-se pontuar as diversas barreiras que limitam uma publicação de ser indexada na SCOPUS, uma delas é a barreira linguística dos pesquisadores, pois a base de dados comporta artigos majoritariamente em inglês.

Outra possibilidade de causa para a falta de resultados nacionais é a falta de investigações sobre o tema no meio acadêmico brasileiro, visto que também foram realizadas buscas em base de dados brasileiras e não foram localizados um grande número de publicações sobre a temática e menos ainda com o interesse de recorte desta investigação. Foram realizadas buscas na base BRAPCI (2019) e não foram localizados resultados significativos sobre a temática aqui analisada. Porém, pesquisas relevantes sobre o tema, como as apresentadas pela NIC.br não foram localizadas em base de dados com alcance internacional como a SCOPUS, o que evidencia que existem produções sérias sobre o tema no Brasil, mas que por diversos motivos que desconhecemos não conseguem alcance em base de dados internacional.

Outro aspecto observado foi a frequência de publicações ao ano durante o período estudado, conforme ilustra o gráfico 2 .

FIGURA 2

Número de documentos recuperados por ano de publicação

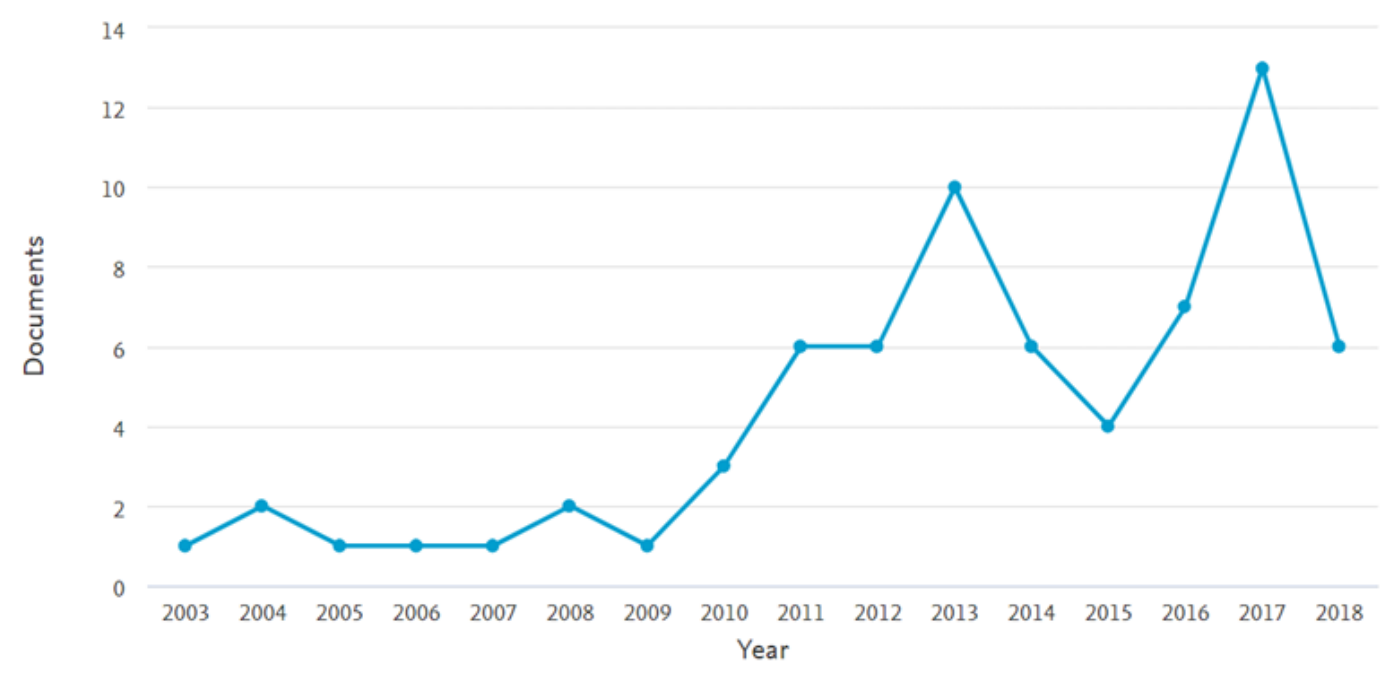

Fonte: SCOPUS, dados da pesquisa.

Observa-se no gráfico 2 que a partir de 2009 houve o início de uma tendência de crescimento que teve o pico em 2013 com 10 publicações. Após um período retração nas publicações entre 2013 e 2015, alcançou em 2017 o maior número de publicações 13, porém em 2018 foram apenas seis documentos sobre o assunto indexados na base de dados.

Em relação ao tipo de documento, os itens em análise se dividem da seguinte maneira: 
FIGURA 3

Número de documentos recuperados por tipo/formato

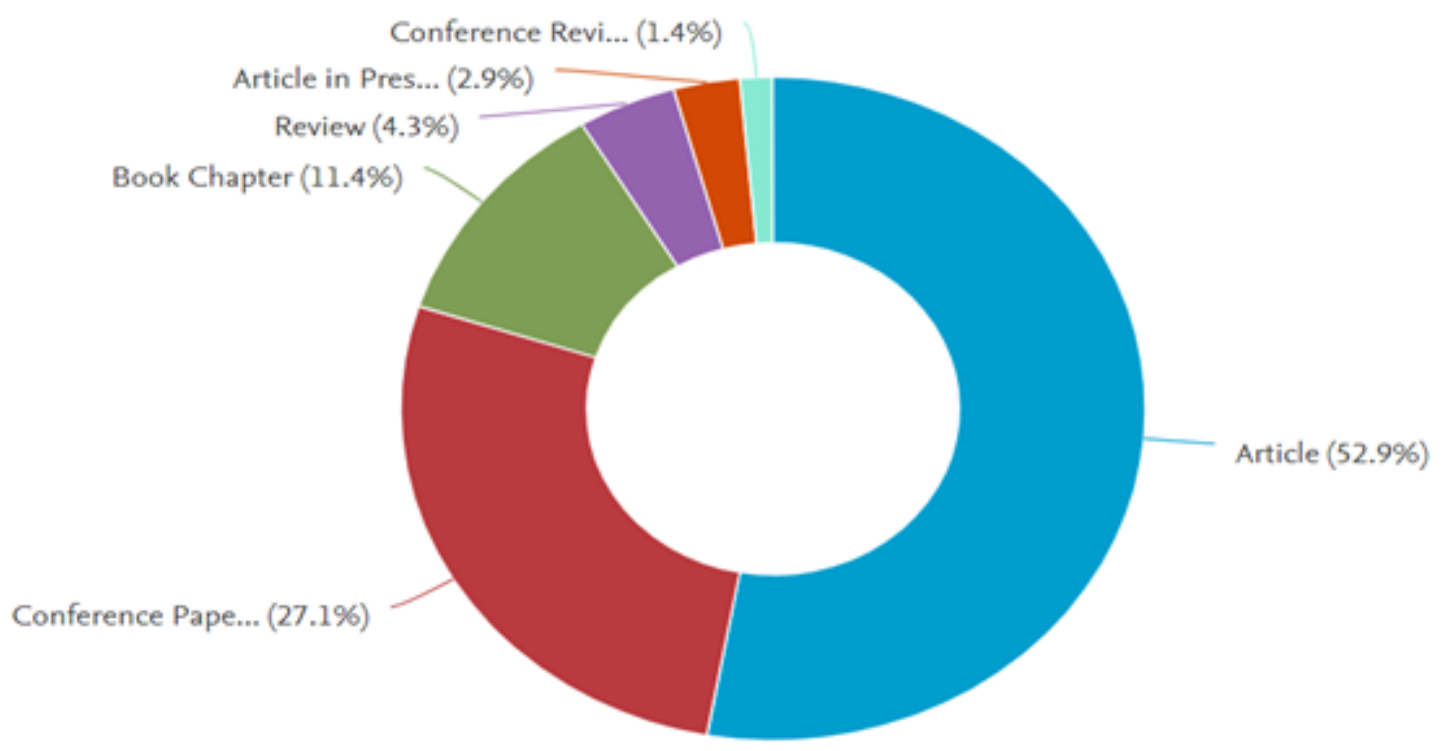

Fonte: SCOPUS, dados da pesquisa.

Observa-se no Gráfico 3 que, dos 71 itens selecionados, 52.9\% são artigos publicados em periódicos, que se pode somar a mais $2,9 \%$ de artigos que estão prestes a serem publicados. Isto demonstra que provavelmente são decorrentes de pesquisas, visto que boa parte dos periódicos é acadêmica. Este número é seguido por trabalhos de anais de evento, com $27.1 \%$ dos materiais recuperados e $11.4 \%$ se tratam de capítulos de livros. Conforme indica o gráfico 4, dentre os 10 autores com maior produção em ordem decrescente estão: Xu, H.; Abbas, J.; Agosto, D. E; Atkison, S.; Carroll, J.M.; Finkelhor, D. Hartikainen, H.; Livari, N.; Kinnula, M.; Mitchell, K. J. As publicações foram realizadas em parceria de até três autores. 
FIGURA 4

Número de publicações por autor

Documents by author

Compare the document counts for up to 15 authors

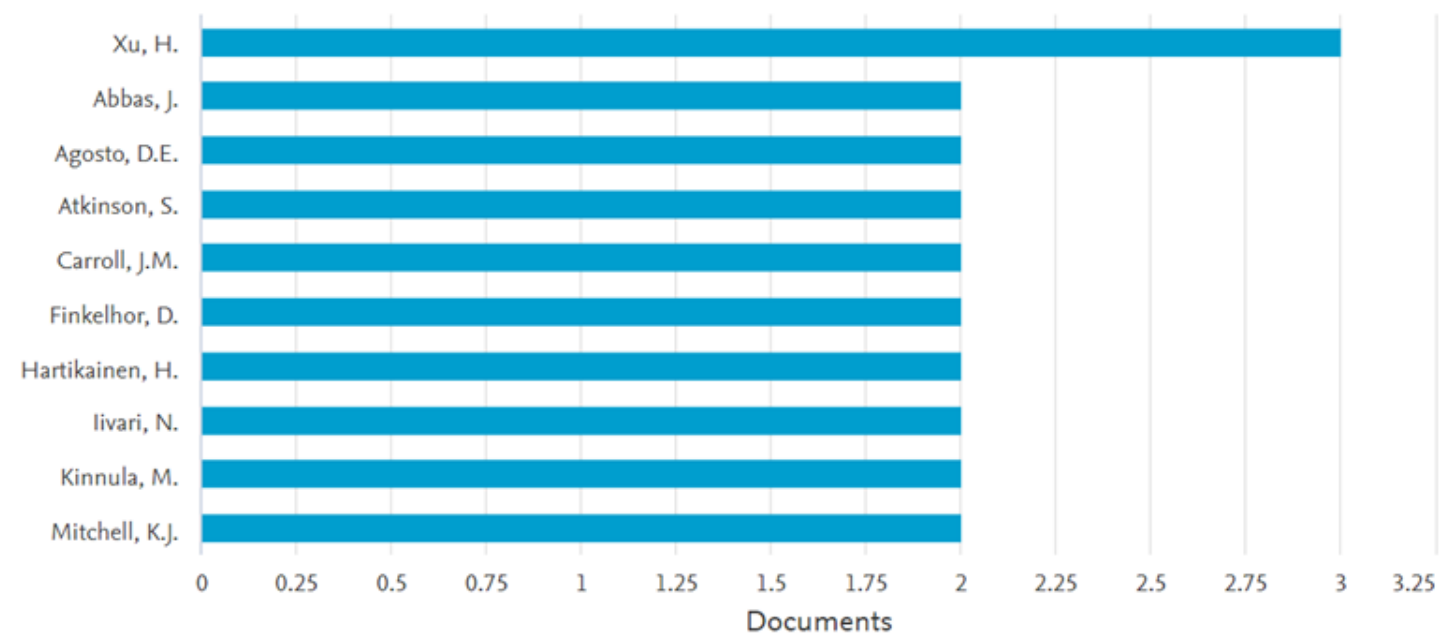

Fonte: SCOPUS.

O gráfico 4 demonstra a baixa produção sobre a temática por um mesmo autor, porque em 16 anos, de 2003 a 2018, o autor com maior produção, tem somente três publicações indexadas na base, de um total de 71 referências selecionadas. Este dado também demonstra a falta de continuidade nas pesquisas pelo mesmo autor, o que traria uma maior solidez na abordagem o assunto, os demais autores têm apenas duas publicações ou menos.

Para levantar as instituições que mais têm se dedicado ao tema, foi verificada a informação sobre filiação dos autores, que foi complementada com busca na internet sobre as instituições citadas. Pode-se verificar que as três primeiras autoras: Henge Xu, Faculdade de Ciência da informação e Tecnologia da Pensilvânia; Junne Abbas, Universidade de Oklahoma; Denise E. agosto, Universidade Drexel são de instituições dos EUA.

Um outro aspecto interessante de se analisar, como citado anteriormente neste artigo, são as diferentes áreas do conhecimento e subtemas pesquisados, dentro da temática uso seguro da informação. 
FIGURA 5

Número de documentos por área de assunto:

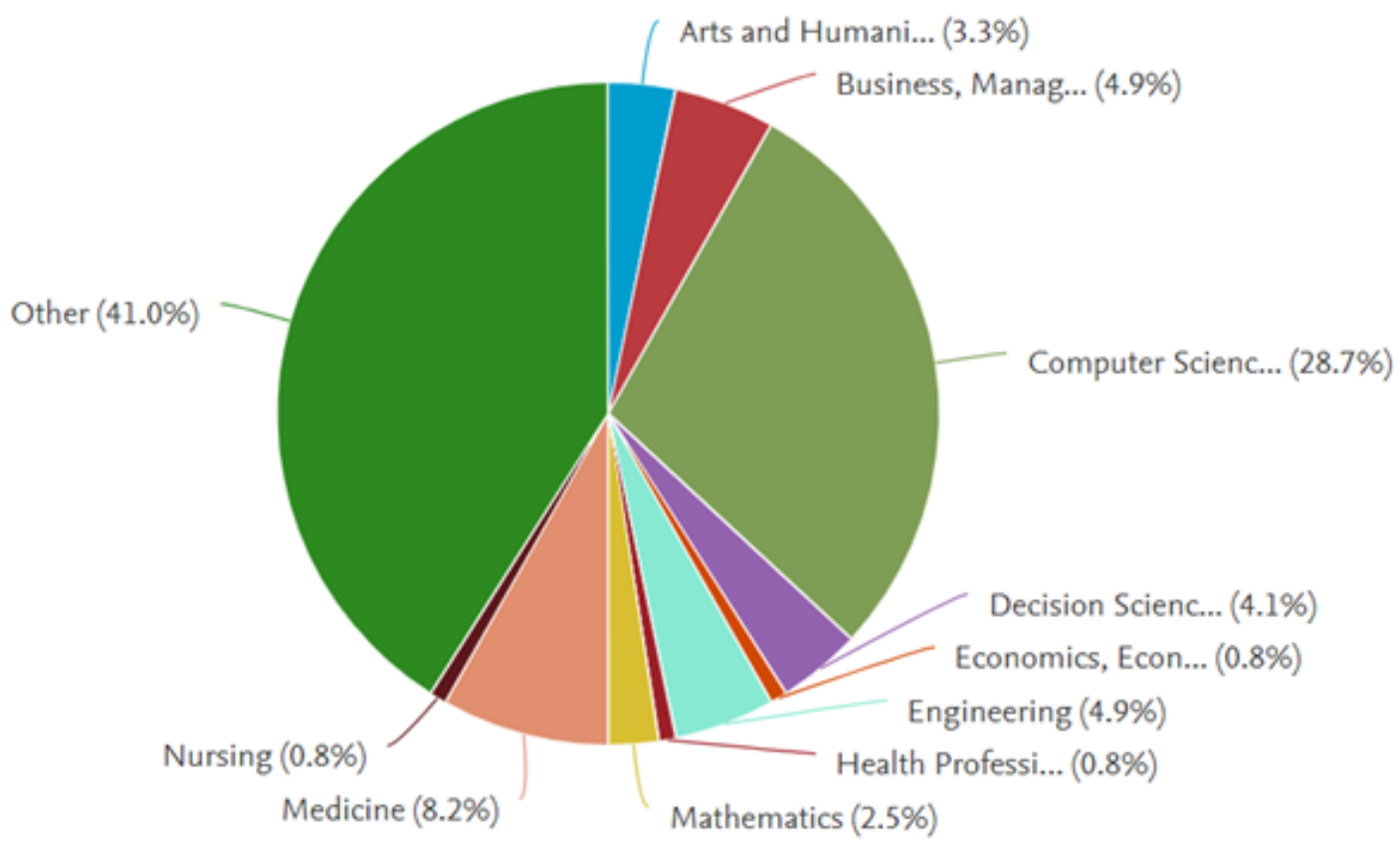

Fonte: SCOPUS, dados da pesquisa.

Conforme o gráfico 5, observa-se que $28.7 \%$ das referências são relacionadas a ciência da computação, 4.9\% administração e engenharia e somente 3.3\% às humanidades. Estes dados que demonstram a existência de poucas pesquisas na área de ciências humanas e muito menos relacionadas à Ciência da Informação, enfocando a educação de usuários da internet para uma navegação mais segura.

Além das 10 áreas do conhecimento especificadas no gráfico 5, 41\% dos artigos são de áreas diversas, o que demonstra a complexidade e dispersão de áreas que têm se dedicado ao estudo desta temática e dificulta a seleção dos documentos recuperados em buscas.

Foi analisada ainda qual a abordagem do tema em cada documento selecionado, através da verificação dos metadados de cada texto. Conforme aponta o gráfico 6 , foram identificadas nove categorias. 
FIGURA 6

Número de documentos por categorias de assunto:

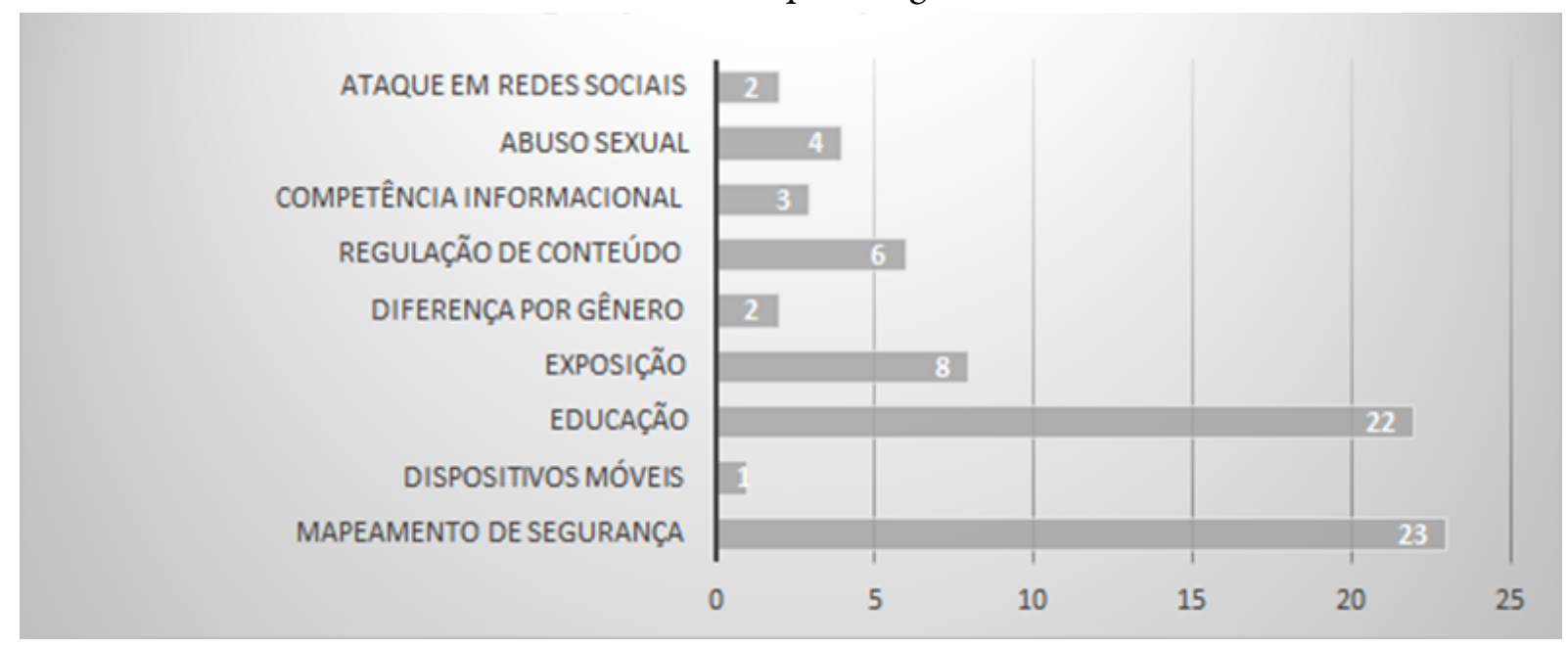

Fonte: elaboração própria.

Ao observar o gráfico 6, percebe-se as principais abordagens são: mapeamento de segurança, com 23 referências, o que demonstra um período de compreensão do fenômeno em que os trabalhos buscam esquematizar e estruturar a forma como se deve desenvolver as habilidades e atitudes seguras nas redes sociais; 22 trabalhos são sobre educação, em que estão agrupados aqueles que abordam assuntos como: $o$ conceito de internet na visão dos estudantes, desenvolvimento de um modelo de navegação segura para estes usuários em específico, a intervenção familiar na assimilação de uma navegação segura, identificação de riscos existentes na navegação e o que as escolas têm feito para uma melhorar a navegação segura. Os estudos desta categoria procuram entender o fenômeno, no caso o uso da internet por crianças e adolescentes, e discute-se como trabalhar estas questões na educação. Porém, pode-se inferir através dos dados numéricos que, assim como os autores destes trabalhos têm interesse em mapear a questão, procura-se também desenvolver ações preventivas de forma prática, não somente teórica, pois a educação dos estudantes ocorre simultaneamente aos estudos. Não se pode esperar o desenvolvimento de uma fundamentação teórica excelente para somente depois colocá-la em prática, tendo em vista a prevenção de prejuízos na aprendizagem dos estudantes.

Em seguida estão trabalhos sobre a exposição de dados pessoais na Internet, com oito referências selecionadas, que discutem diversos tipos de exposição, como: localização geográfica ou envio de fotos pessoais; seis trabalhos discutem a regulação de conteúdo que se veicula pela internet, discutindo a necessidade de criação de políticas públicas; quatro trabalhos abordam sobre abuso sexual, incluindo a vulnerabilidade em especial de crianças na Internet; três abordam a Competência Informacional, ou seja, como desenvolver as habilidades necessárias para o uso seguro da internet; dois abordam a diferença de comportamento online por gênero, que envolvem a leitura de comportamento que determinada sociedade espera da performance do homem e da mulher e como estas leituras de gênero se reflete no uso das redes sociais; outros dois trabalhos são sobre Ataques em Redes Sociais, roubo de senha ou bullying digital; um trabalho discute o uso específico de mídia, o dispositivo móvel.

\section{Conclusões}

No Brasil, a NIC.Br tem desenvolvido grande parte das pesquisas sobre o uso seguro da internet, inclusive algumas delas em parceria com a EU Kids on line, o que nos traz um conjunto de resultados importantes para discussão da temática. 
Com a análise das 71 referências, temos uma frequência de itens que buscam mapear os diferentes grupos que estão envolvidos no uso seguro da informação por crianças, como pais, nível escolar, nível de desenvolvimento, entre outros.

Com o uso cada vez maior da internet e cada vez mais cedo, torna-se imprescindível desenvolver habilidade de estudantes para o uso adequado desta ferramenta. Assim, a escola ocupa um papel de grande responsabilidade neste processo.

As pesquisas brasileiras demonstraram que a biblioteca ocupa um dos três lugares em que mais se utiliza a internet na escola privada e primeiro lugar na escola pública, o que enfatiza a importância do bibliotecário escolar se apropriar do tema e desenvolver habilidades informacionais relacionadas à segurança da informação.

O grande uso das redes sociais tem exposto os estudantes as mais diversas situações de vulnerabilidade no mundo online. A escola deve estender a orientação dos alunos sobre os riscos existentes aos responsáveis por eles, para que de forma conjunta se consiga um maior acompanhamento dos estudantes, principalmente em relação à exposição excessiva dos mesmos na internet. Exposição que em geral são realizadas a partir de suas próprias casas.

Infelizmente observa-se no Brasil o número crescente de ataques em locais públicos como: escola, igrejas e boates e muito deles são praticados por estudantes que foram encorajados a cometerem esses atos, estimulados por participação em grupos de discussão por aplicativos online. Isso demonstra a gravidade que o problema tem tomado em nossa sociedade.

Com o aprofundamento, orientação e discussão sobre a temática, a escola poderá trabalhar para o desenvolvimento de habilidades, que possam resultar em comportamentos e atitudes mais seguros no ambiente online.

Ao longo do artigo pode-se observar a abrangência que a temática, uso seguro da informação na internet, alcança a necessidade de uma sistematização de orientações sobre os assuntos que a escola deve abordar. A BNCC traz algumas habilidades a serem desenvolvidas, porém, acredita-se exigir direcionamentos mais específicos nas diferentes disciplinas. Esta diversidade de assuntos, dentro de um mesmo tema, nos faz perceber a complexidade existente na pesquisa sobre o mesmo assunto e o quanto a temática carece de pesquisas para solucionar ou amenizar as diferentes questões principalmente relacionadas às crianças e adolescentes.

Como direcionamento de interesse para pesquisas futuras, acredita-se que se deveria ter como ponto de partida ao se discutir a temática, o conceito de internet que os estudantes/ grupo observado nas pesquisas têm sobre o assunto. Edwards, Nolan, Henderson, Mantila, Plowman e Skouterls (2018), por exemplo, discutem as ideias de Vygotsky sobre "conceitos cotidianos" e "conceitos científicos/ maduros" e os aplica na compreensão da questão, principalmente em pesquisas direcionadas a estudantes.

De forma geral utiliza-se dos conceitos cotidianos da Internet e de seu entorno para construir conceitos maduros da Internet. Os educadores com esta compreensão buscariam compreender este conceito cotidiano e desenvolver o conhecimento maduro, tendo também por base a segurança da informação.

\section{REFERÊNCIAS}

BRAPCI. Disponível em http://www.brapci.inf.br/index.php/res/

Brasil. Lei $n^{\circ} 12.965$ (23 de abril de 2014). Estabelece princípios, garantias, direitos e deveres para o uso da Internet no Brasil. Marco Civil da Internet. Disponível em http://www.planalto.gov.br/ccivil_03/_ato2011-2014/2014/le i/l12965.htm

Casarin, H. C. S. (2017). Competência informacional e midiática e a formação de professores de ensino fundamental: um relato de experiência. Revista brasileira de biblioteconomia e documentação,13 (Especial), 301-321. Disponível em http://hdl.handle.net/20.500.11959/brapci/2012 
Comitê Gestor da Internet no Brasil (2014). TIC kids on line Brasil 2014. Disponível em: https://cetic.br/media/do cs/publicacoes/2/TIC_Kids_2014_livro_eletronico.pdf

Dias, G. A. e Cavalcante, R. A. (2016). As tecnologias da informação e suas implicações para a educação escolar: uma conexão em sala de aula. Revista de pesquisa interdisciplinar. 1, 160-167. Disponível em http://revistas.ufcg.edu .br/cfp/index.php/pesquisainterdisciplinar/article/view/80/59

Edwards, S.; Nolan, A.; Henderson, M.; Mantila, A.; Plowman, L. e Skouterls H. (2018). Young children's everyday concepts of the internet: a platform for saber-safety education in the early eyears. British journal of educational technology.49 (1), 45-55. Disponível em https://onlinelibrary.wiley.com/doi/epdf/10.1111/bjet.12529

EU Kids Online. Protecting children's data Online: preliminary results of the EU Kids Online survey. Disponível em http://www.lse.ac.uk/media-and-communications/assets/documents/research/eu-kids-online/news/pressreleases/SID-2019-Press-Release.pdf

Haynes, D., Robinson, L. (2014). Defining user risk in social networking services. Aslib Journal of information management. 67(1), 94-115. Disponível em http://openaccess.city.ac.uk/6228/

Magrani, E. (2018). A internet das coisas. Rio de Janeiro: FGV Editora.

Ministério da Educação (2018). Base Nacional Comum Curricular - BNCC. Brasília: Ministério da Educação.

Núcleo de informação e Coordenação do Ponto BR (NIC.br) (2018). Pesquisa sobre o uso das tecnologias de informação e comunicação nas escolas brasileiras: TIC educação 2017. NIC.br. Disponível em https://www.nic.br/media/do cs/publicacoes/2/tic_edu_2017_livro_eletronico.pdf

ONU (2015). Transformando nosso mundo: a agenda 2030 para o Desenvolvimento Sustentável. Disponível em https ://nacoesunidas.org/pos2015/agenda2030/

Paulo, R. B. (2016). Atuação do bibliotecário na formação de professores do ensino fundamental para o desenvolvimento da competência informacional: uma experiência na rede da educação municipal de Marília-SP. Dissertação de mestrado. Universidade Estadual Paulista - UNESP - Marília.

Santaella, L.; Gala, A.; Policarpo, C. e Gazoni, R. (2013). Desvelando a Internet das coisas. Revista GEMInIS. 4 (2), 19-32. Disponível em http://www.revistageminis.ufscar.br/index.php/geminis/article/view/141/pdf

SCOPUS. Disponível em https://www.elsevier.com/solutions/scopus/how-scopus-works/content

UNESCO (2013). Alfabetização midiática e informacional: currículo para formação de professores. Brasília: UNESCO, UFTM. Disponível http://www.unesco.org/new/en/communication-and-information/resources/publication s-and-communication-materials/publications/full-list/media-and-information-literacy-curriculum-for-teacher s/

UNESCO (2016). Alfabetização midiática e informacional: diretrizes para a formulação de políticas e estratégias. Brasília: UNESCO, Cetic.br. 204 . Disponível em https://unesdoc.unesco.org/ark:/48223/pf0000246421

Uribe Tirado, A. (2009). Interrelaciones entre veinte definiciones-descripciones del concepto de alfabetización en información: propuesta de macro-definición. ACIMED, 20, (4), 1-22. Disponível em http://eprints.rclis.org/ $14145 /$ 